\title{
Systems of conductive skin for power transfer in clinical applications
}

\author{
Andreas P. Kourouklis ${ }^{1}$ (1) $\cdot$ Julius Kaemmel ${ }^{3} \cdot \mathrm{Xi} \mathrm{Wu}^{1} \cdot$ Evgenij Potapov $^{3} \cdot$ Nikola Cesarovic $^{3,4} \cdot$ Aldo Ferrari $^{2}$. \\ Christoph Starck ${ }^{3} \cdot$ Volkmar Falk $^{3,4} \cdot$ Edoardo Mazza $^{1,2}$
}

Received: 7 April 2021 / Revised: 29 July 2021 / Accepted: 12 August 2021 / Published online: 3 September 2021

(c) The Author(s) 2021

\begin{abstract}
The primary aim of this article is to review the clinical challenges related to the supply of power in implanted left ventricular assist devices (LVADs) by means of transcutaneous drivelines. In effect of that, we present the preventive measures and post-operative protocols that are regularly employed to address the leading problem of driveline infections. Due to the lack of reliable wireless solutions for power transfer in LVADs, the development of new driveline configurations remains at the forefront of different strategies that aim to power LVADs in a less destructive manner. To this end, skin damage and breach formation around transcutaneous LVAD drivelines represent key challenges before improving the current standard of care. For this reason, we assess recent strategies on the surface functionalization of LVAD drivelines, which aim to limit the incidence of driveline infection by directing the responses of the skin tissue. Moreover, we propose a class of power transfer systems that could leverage the ability of skin tissue to effectively heal short diameter wounds. In this direction, we employed a novel method to generate thin conductive wires of controllable surface topography with the potential to minimize skin disruption and eliminate the problem of driveline infections. Our initial results suggest the viability of the small diameter wires for the investigation of new power transfer systems for LVADs. Overall, this review uniquely compiles a diverse number of topics with the aim to instigate new research ventures on the design of power transfer systems for IMDs, and specifically LVADs.
\end{abstract}

Keywords Left ventricular assist devices (LVAD) - Cardiac implantable electronic device (CIED) · Driveline infections (DLIs) $\cdot$ Foreign body reaction (FBR) $\cdot$ Surface topography $\cdot$ Biofilm

\section{Introduction}

The emergence of digital technology catalyzes a generation of medical breakthroughs and offers unprecedent access to the management of human disease (Topol 2019). Along this

Special Issue: Nanoengineering for Mechanobiology.

Andreas P. Kourouklis

akourouklis@ethz.ch

1 Department of Mechanical and Process Engineering, Institute for Mechanical Systems, ETH Zurich,

Leonhardstrasse 21, 8092 Zurich, Switzerland

2 EMPA, Swiss Federal Laboratories for Material Science and Technology, Überlandstrasse 129, 8600 Dübendorf, Switzerland

3 Department of Cardiothoracic and Vascular Surgery, German Heart Center Berlin, Augustenburger Platz 1, 13353 Berlin, Germany

4 Department of Health Sciences and Technology, ETH Zurich, 8093 Zurich, Switzerland line, the widespread use of digital hardware, such as smart phones and wearable sensors, has inspired significant innovations on the design of novel diagnostic solutions (Chandrasekhar et al. 2018; Yang et al. 2020). On a similar track, harnessing the strengths of cutting-edge technologies has the potential to benefit thousands of patients receiving implanted medical devices (IMDs) with therapeutic electromechanical function, such as cardiac implantable electronic devices (CIEDs) and left ventricular assist devices (LVADs). The latter type of medical intervention poses a non-trivial challenge which primarily pertains to the development of suitable power transfer systems for supporting the requirements of different IMDs, Fig. 1. Comparing commonly used IMDs in patients with cardiac problems, LVADs consume significantly higher power $(\sim 7 \mathrm{~W})$ than defibrillators $\left(10^{-3} \mathrm{~W}\right)$ and pacemakers $\left(10^{-6} \mathrm{~W}\right)$ (Ben Amar et al. 2015). For this reason, the use of well-insulated transcutaneous metallic wires (e.g., drivelines) is the only available commercial solution that is currently applied with LVADs. On the contrary, wireless (e.g., flexible electronics: $\sim 10^{4} \mathrm{~S} / \mathrm{m}$ ) and less invasive 


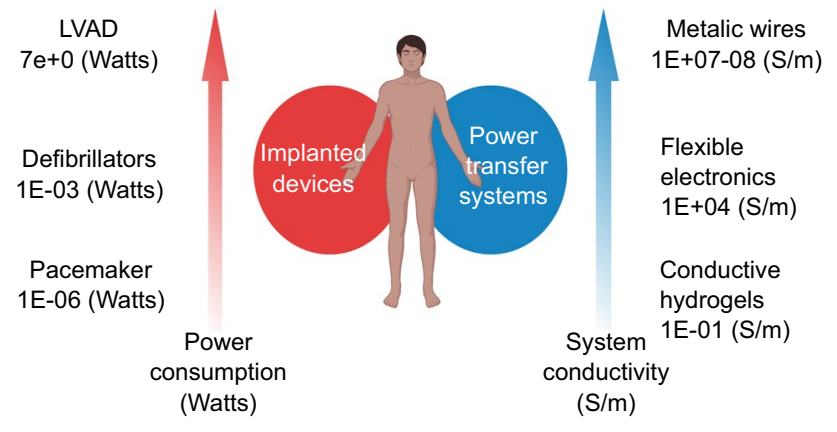

Fig. 1 Different IMDs and power transfer systems combined for the therapeutic benefit of human patients. Increased transparency of the red arrow reflects IMDs with lower power consumption. On the right side, selected power transfer systems to support the function of IMDs. Increased transparency of the blue arrow corresponds to power transfer systems with lower electrical conductivity. Currently, drivelines composed of insulated metallic wires are the only conductive system which is compatible with LVADs

solutions (e.g., conductive hydrogels: $\sim 10^{-1} \mathrm{~S} / \mathrm{m}$ ) for power transfer are not sufficient to support LVADs due to the significantly lower electrical conductivity compared to metallic wires $\left(\sim 10^{7}-10^{8} \mathrm{~S} / \mathrm{m}\right)$ (Kim et al. 2011; Sirivisoot et al. 2014).

LVADs, which are on the spotlight of this review, expose patients to the risk of infection and foreign body reaction as part of short- and long-term pathological responses, respectively (Zinoviev et al. 2020). A leading cause of infections in LVADs is the use of percutaneous LVAD drivelines to convey power and information through the human body. Although wireless solutions of power transfer may be resolutive, their clinical implementation faces technical challenges and is still far from becoming part of the mainstream clinical practice. Therefore, power drivelines remain the most reliable strategy to cover the power requirements of LVADs, urging the need to generate new driveline systems with improved biological compatibility and optimal power characteristics.

Here, motivated by the cause-to-effect relationship between percutaneous LVAD drivelines and the risk of infections, we present different in vitro and in vivo models of the skin that may be used to identify critical factors for the progression of infections. Furthermore, we review a number of alternative technological solutions for the effective and less destructive transfer of power in IMDs. Finally, we propose the creation of conductive skin systems with highconductivity components as an innovative solution towards the risk-free and long-term integration of power and signal drivelines connected to IMDs. Altogether, this essay provides a critical perspective on the current challenges and opportunities associated with power transfer in the human body, with the objective of drawing new directions on the design of biologically compatible and infection-free IMDs, such as LVADs.

\section{Clinical challenges associated with the power transfer of LVADs}

LVADs are implanted in adult patients with heart failure (HF) to restore blood perfusion back to physiological levels. About half of the LVADs implanted nowadays serve as destination therapy (Kirklin et al. 2017), while the rest address the following treatment strategies: bridge to transplantation, bridge to candidacy and bridge to recovery (Ponikowski et al. 2016). Together with the increasing number of patients with end-stage HF and the shortage of donors for organ transplantation, the advancements in LVAD technology led to the preferential use of LVADs in the form of destination therapy. Current state of the art LVADs include an implanted pump connected to an external battery and a controller via a well-insulated percutaneous driveline (Schmid Daners et al. 2017). However, LVADs can also become subject to major complications, including driveline-specific infections (DLIs) (Hannan et al. 2019). Relevant epidemiological studies reveal at least one incidence of DLI in the first year of LVAD support for $19 \%$ of the patients, while the peak of incidence occurs at approximately 6 months after implantation (Goldstein et al. 2012; Pavlovic et al. 2019).

DLIs are associated with the full skin injury and the ongoing percutaneous presence of LVAD drivelines that together impair the process of wound healing. Skin is composed of several layers with distinct contributions into the process of wound healing (Kwon et al. 2018; Rodrigues et al. 2019). The epidermis contains a stratified epithelium that mediates barrier function against external environmental factors. Anchored to that, the fibroblast-rich dermis has a substantial role into the mechanical properties of the skin tissue. Wound healing is a multi-step process that involves blood clot formation, inflammation, re-epithelialization, tissue granulation, neovascularization, and tissue contraction (Rousselle et al. 2019; Shaw and Martin 2009). During reepithelialization, keratinocytes migrate towards the injured tissue to re-establish a new epithelium (Bamberger et al. 2005). However, the implanted LVAD drivelines occupy the center of the wound, altering the biomechanical and biochemical features of the injured site in a manner that burdens keratinocyte migration from the margins to the center of the scission (Pensalfini et al. 2018; Wahlsten et al. 2019; Wietecha et al. 2020).

In addition to that, previous studies suggest a no-slip condition between keratinocytes and LVAD drivelines, which promotes distal epidermal growth and subsequently sulcus formation around the drivelines (Großhauser et al. 2015). 
(b)

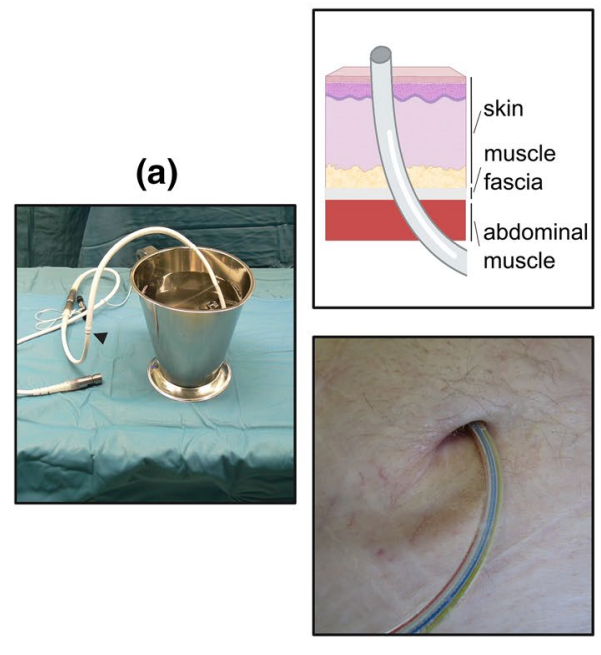

Fig. 2 Percutaneous LVAD drivelines may be subject to infections. (a) Pre-implanted LVAD driveline with the velour section immersed in the container. (b) Implanted LVAD driveline through the human skin. The lower image depicts an infection-free exit of the percutaneous LVAD driveline. (c) Biofilm formation at the upper layers of the human skin may lead to superficial infection sparing the mus-

In effect of that, the weak sealing between epidermis and drivelines gives rise to a durable breach for biofilm formation of fungal and microbial composition, which can further migrate into the skin causing DLI (Qu et al. 2020). Yet, how the intercellular crosstalk between keratinocytes and dermal fibroblasts affects wound healing in the presence of percutaneous drivelines remains unclear. In this direction, forthcoming studies with systematic control on driveline motion, surgical details, and patient health will be critical to investigate the underlying cellular interactions, identifying new therapeutic targets against DLIs (Dean et al. 2015; Zierer et al. 2007).

\section{Clinical protocols against driveline infections (DLIs)}

In the clinical context, LVAD infections are distinguished in three different groups: LVAD-specific, LVAD-related and non-LVAD-related infections. The DLIs, which is a top interest of this review, together with infections of the adjacent tissue belong to the category of LVAD-specific infections. The progress and the severity of DLIs are correlated with the anatomical position of the affected tissue compartments. Specifically, depending on whether the muscle fascia or the deeper muscle tissue is involved (Fig. 2), the DLIs are further split into superficial and deep DLIs, respectively (Hannan et al. 2011). The diagnosis of LVAD-specific infections, and particularly superficial DLIs, is based on the (c)
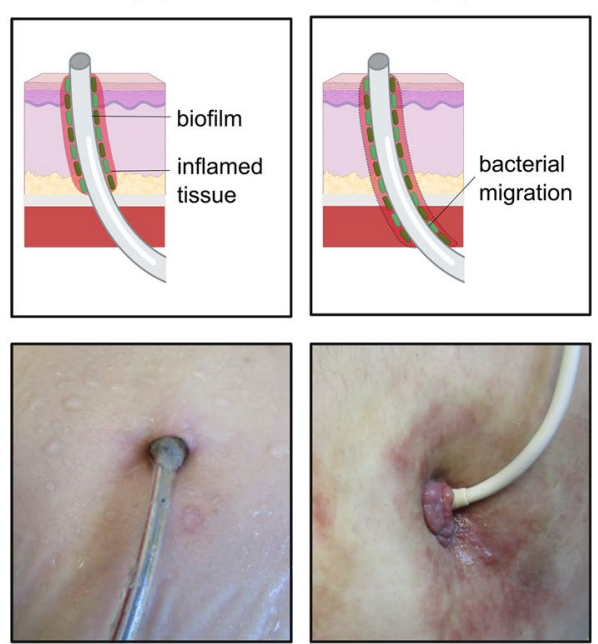

cle fascia. The lower image depicts a patient with superficial infection. (d) Bacterial migration into the lower layers of the skin may lead to deep infection involving the muscle fascia. The lower picture depicts a patient with deep driveline infection. The cartoons of this review were created with the assistance of Biorender.com

detection of several clinical symptoms (erythema, purulent discharge, and increased temperature) together with microbiological, echocardiographic and computed tomography studies (Hannan et al. 2011). Moreover, clinical examinations of white blood cells scintigraphy (de Vaugelade et al. 2019), positron emission tomography-computed tomography (de Vaugelade et al. 2019; Ten Hove et al. 2021) and the combination of fluorescence in situ hybridization and polymerase chain reaction (Schoenrath et al. 2020) ascertain additional diagnostic power to distinguish between superficial and deep infections.

\section{Post-operative protocols}

The majority of DLIs coincide with the presence of Grampositive and Gram-negative bacteria like Staphylococcus aureus and Staphylococcus epidermidis, while the strain of Pseudomonas aeruginosa leads the Gram-negative category. Even rarely, fungal, viral and protozoal pathogens may also trigger DLIs with life threatening effects (Hannan et al. 2019; Qu et al. 2021; Zinoviev et al. 2020; Maly et al. 2014). The standard treatment against DLIs combines antiinfective therapeutic protocols with specialized procedures of wound therapy and surgical intervention. A challenging factor against the elimination of bacterial pathogenesis comes from biofilm formation at the interface of drivelines with the injured skin (Fig. 2b). Correct evaluation of the biofilm's age is critical for the selection of anti-infective agents 
that can either eradicate or suppress pathogen distribution (Trampuz et al. 2020).

Another possible route to tackle severe DLIs is the treatment by means of surgical interventions, such as driveline relocation with wound debridement (Kusne et al. 2017; Pieri et al. 2016; Trampuz et al. 2020). Equally critical is the practice of meticulous wound care protocols that are well adjusted to the needs of the different stages of DLIs. The progression of DLIs and the characteristics of percutaneous wounds are strong determinants of the selected therapeutic protocol, that can involve wound dressing in combination with supplementary treatments, such as negative pressure vacuum-assisted closure therapy, cold atmospheric plasma, and antibiotic beads (Bernhardt et al. 2020; Haddad et al. 2020; Hilker et al. 2017; Kilo et al. 2020; Sezai et al. 2020). In many cases however, the therapeutic benefits are decapacitated by relapsing infections related to biofilm persistence. Against this adversity, additional therapeutic support may include bacteriophage treatment, long-term suppression antibiotic therapy, and as a last option device exchange (Kusne et al. 2017; Mulzer et al. 2020).

\section{Preventive measures}

To avoid the post-operative escalation of DLIs, the clinical procedures have also adopted an array of preventive measures. A key element for the prevention of LVAD infections is the administration of perioperative anti-microbial prophylaxis, similar to other types of cardiac surgery (Kusne et al. 2017). This treatment is further combined with surgical protocols, such as the double tunneling method to inhibit ascending DLIs (Fleissner et al. 2013; Wert et al. 2018). Other strategies focus on trauma prevention and its impact on the risk of infection. To this end, surgical sutures are regularly applied to stabilize drivelines at the exit site, limiting the extend of injury from potential mechanical motions (Kusne et al. 2017).

On the sidelines, the management of post-operative complications, including acute infections, is starting to be largely recognized and has led to the introduction of protective envelopes which support the controlled release of antibiotics for at least 1 week after deployment (Biffi 2019). Although this strategy has not been tested in LVAD protocols, the use of drug-eluting polymeric envelope around CIEDs in a large clinical trial was proven more effective compared to simple flushing of the generator pocket and ensuing systemic treatment (Krahn et al. 2018; Tarakji et al. 2019). Based on these results, novel strategies for the use of antibiotic envelopes in combination with neurostimulators (e.g., deep brain, sacral nerve, vagus nerve stimulators) and LVADs shall be subject to further studies to gain indications relevant to driveline protection.

\section{Skin models for the study of driveline infections}

\section{In vitro models of human skin}

The percutaneous implantation of LVAD drivelines comes together with a series of mechanical and chemical stressors that can facilitate the progression of DLIs. However, the mechanisms that drive cellular responses around the drivelines elude our understanding due to the shortage of available patients for exploratory mechanistic studies. To this end, in vitro systems that recapitulate critical conditions of skin physiology may be used to uncover the mechanisms downstream of driveline-generated stressors. A large number of in vitro skin models are built through a bottom-up approach (Randall et al. 2018), where an initially formed dermal scaffold supports the organization of an upper epidermal layer. This artificial epidermis is regularly comprised of keratinocyte cells, attaining a platform to investigate various mechanisms, such as wound healing and regeneration (Deshayes et al. 2018). Similar in vitro systems can also host studies for the evaluation of new biocompatible and infection-resistant percutaneous devices (Bolle et al. 2020a, b) or to simply uncover the individual effects of different bacterial strains (Jahanshahi et al. 2020; Koval et al. 2019; Popov et al. 2014; Zinoviev et al. 2020). In spite of this potential, the majority of in vitro skin models are deprived of an efficient circulatory network, hindering its exposure to biologically relevant immune responses (Kim et al. 2019; Miyazaki et al. 2019; Saleh and Bryant 2017). In contrast, natural skin explants of human and animal origin sustain an organotypic complexity which is associated with pathological responses, such as foreign body reaction (FBR) and infection (Dellambra et al. 2019; Griffin et al. 2020; Maboni et al. 2017; Rakita et al. 2020; Schaudinn et al. 2017; Torres et al. 2020; Yoon et al. 2019). Future development in this direction shall include the implantation of percutaneous drivelines in perfusable skin explants to further elucidate the dynamic biological signals that instruct DLIs (Moniz et al. 2020; Ternullo et al. 2017).

\section{Animal models}

In vivo models have been largely used to capture the progression of DLIs and FBR in pre-clinical studies (Dondossola et al. 2016; Greenfeld et al. 1995; Isenhath et al. 2007; Jarvik et al. 1998; Toba et al. 2011; von Bayern 
et al. 2008; Zierer et al. 2007). The selection of a particular animal model is influenced by several factors, such as the driveline system, the conditions of animal handling, the investigated bacterial strain, and the desired standards for physiological resemblance to the human skin (Carney et al. 2009; von Bayern et al. 2008). In this case, large animals are usually preferred for the exploration of promising LVAD technologies, especially due to adequate surgical space in favor of animal comfort and surgical precision (Carney et al. 2009; Kitao et al. 2011; McGee et al. 2014; Monreal et al. 2014; Tuzun et al. 2007; Weiss et al. 2012). Among larger animals, the physiology of the porcine skin closely resembles that of human (Ashara and Shah 2016; Grada et al. 2018; Tsai et al. 2019; Vodička et al. 2005). Yet, many driveline studies employ goats or sheep that enable driveline stabilization onto a minimally perturbing dorsal site which is further protected by specialized protective vests and amenable breeding conditions (Carney et al. 2009; Großhauser et al. 2015; Lee et al. 2013). In conclusion, the selection of different skin models is well correlated with the leading pre-clinical questions and the most recent standards for animal welfare. In this direction, the rigorous pre-clinical assessment of DLIs shall put together a combinatorial strategy to harness the distinct advantages of more than one category of the aforementioned skin models.

\section{Foreign body reaction, lessons from the past}

A critical condition for the successful incorporation of IMDs in a host organism is related with their capacity to minimize FBR. This is a common biological challenge that escalates to the assembly of fibrotic capsules around artificial materials comprising IMDs (Anderson et al. 2008). Fibrotic capsules resemble granulation tissues with immature vascularization, which may eventually impede the electromechanical performance of IMDs. For instance, capsule formation around CIEDs attenuate signal transmission in the cardiac tissue, leading to increased power consumption or even local overheating (Dvorak et al. 2012; Li et al. 2020). To combat this problem, previous studies modified implanted devices with different grades of biochemical molecules (Liu et al. 2008; Park et al. 2019; Weigel et al. 2018). Consistent to that, novel biomaterials enable the design of device sleaves that prevent FBR (Davenport Huyer et al. 2020; Robotti et al. 2020), alleviating the mismatch between implants and the tissue microenvironment.

Moreover, the size, microarchitecture, and mechanical properties of implanted objects constitute additional design parameters to mediate the extend of FBR (Helton et al. 2011). For instance, implants of smaller size and lower elastic modulus demonstrate significantly less FBR (Sanders et al. 2002). Likewise, textured surfaces have been shown to weaken FBR, as validated by the formation of thinner and less dense fibrotic capsules (Johansson et al. 2009; Picha and Drake 1996; Ward et al. 2002). These findings underline a mechanistic correlation between the material properties of the implanted objects and the extent of FBR, that shall be harnessed to design new power drivelines with only benign FBR.

\section{Alternative solutions for high-power transfer}

\section{Wireless power transfer}

Wireless power transfer has the potential to solve the problem of DLIs. With this ambitious goal, the transcutaneous energy transfer systems (TETS) are widely investigated with the aim of leading to fully implanted and infectionfree LVADs (Fig. 3a). In one of the first cases that combined TETS in LVAD implantation, the transfer of power was carried out by induction coupling between an external and an implanted coil, after the contactless transmission of direct current through the physiological barrier of the human skin (Leuck 2015; Mehta et al. 2001). Still, formidable technical challenges render wireless solutions unsuitable for the hazard-free support of LVADs.

TETS intolerance to coil misalignment burdens their systematic application to a patient population with varying body types (El-Banayosy et al. 2003; Waters et al. 2014). To tackle this challenge, recent efforts developed free-range resonant electrical energy delivery (FREE-D) systems that employ magnetic resonance to successfully transmit power in both short- and long-range distances (Waters et al. 2018). In a small-scale clinical trial, the use of coplanar energy transfer (CET) proved to be feasible for powering continuous flow LVADs (Pya et al. 2019). Despite the overall progress, the implementation of a wireless-based solution for power transfer in LVADs is far from becoming part of the clinical routine. In this direction, new wireless solutions against tissue overheating and fibrotic responses will be essential to avoid power outage and tissue damage with life threatening consequences (Letzen et al. 2018).

\section{Physical and biological functionalization of power drivelines}

The effects of percutaneous drivelines on the skin tissue may well reflect the bi-directional communication between skin cells and the material properties of LVAD drivelines. This hypothesis is supported by an inherent cellular mechanism which integrates mechanical and biochemical cues of the extracellular environment into downstream signals of tissue 
(a)

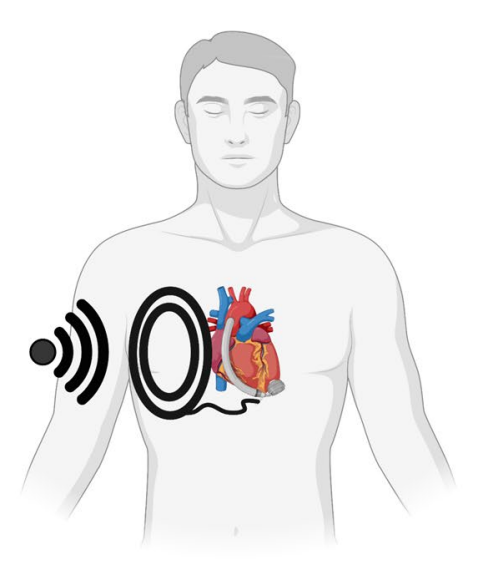

(b)

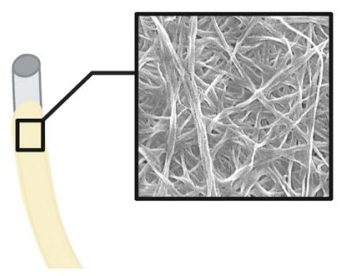

(d)

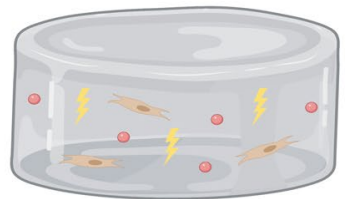

(c)

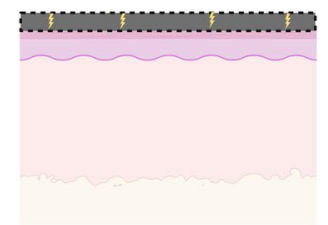

(e)

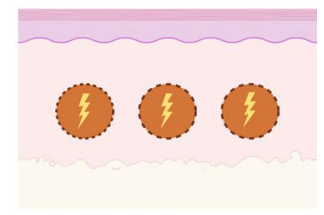

Fig. 3 New solutions for power transfer into the human body with the aim to eliminate the problem of infection. (a) TETS, (b) driveline modification with physical and biological features for enhanced antibacterial properties and integration with skin [inner image depicts anti-fibrotic biosynthesized cellulose (Robotti et al. 2020)], (c) lami- nated flexible electronics on epidermal tissue, (d) conductive biological hydrogels with controlled cellular composition and conductive particles, and (e) new systems of conductive skin accommodating highly conducting metallic wires in 3D skin substitutes. The cartoons were created with Biorender.com repair (Tschumperlin et al. 2018). Up to date, biomaterials with controlled chemistry, stiffness, shape, and surface topography have been successfully formulated to coordinate cellular responses in wound healing and tissue regeneration (D’Ovidio et al. 2019; Guimarães et al. 2020; Kaylan et al. 2017; Kourouklis et al. 2014; Li et al. 2017; Murray et al. 2019; Ragelle et al. 2018; Rahmati et al. 2020; Tylek et al. 2020). In the same context, the material properties of the drivelines may interfere with the cellular functions in the proximal skin tissue. Thus, the design of drivelines with controlled presentation of biochemical and biophysical cues (Fig. 3b) offers an alternative strategy for instructing tissue responses that reduce the chance of DLI.

Previous clinical studies showed that the smooth silicone jacket of HeartMate II drivelines attaches more firmly onto the wound compared to porous velour (McCandless et al. 2015), suggesting that the physical characteristics of LVAD drivelines can influence their interaction with injured skin. In contrast, the incorporation of porous features on the surface of exploratory percutaneous devices corresponded to enhanced dermal and epidermal incorporation without evidence of infection in mouse studies (Fukano et al. 2010). Interestingly, mock drivelines modified with a fibrous surface demonstrated strengthened adhesion with human skin equivalents (HSE) (Bolle et al. 2020a). For the same in vitro set up, however, the percutaneous implantation of the fibrous mock drivelines into HSE did not inhibit downward epidermal growth (marsupialization) which is a histological condition connected with infected percutaneous LVAD drivelines. Apart from the surface features, the size and stiffness of the drivelines may also affect the progression of DLIs.
In a relevant clinical study, the thinner and more compliant drivelines, as indicated by the force load $(\mathrm{N})$ required to push a gauge to a certain distance $(5 \mathrm{~mm})$ against the drivelines, restricted complications related to percutaneous implantation (Imamura et al. 2017). Specifically, HeartMate II drivelines (Diameter $(D) \sim 6 \mathrm{~mm}, 3 \mathrm{~N}$ ) induced fewer cases of DLIs compared to the larger and stiffer drivelines of DuraHeart $(D \sim 9 \mathrm{~mm}, 40 \mathrm{~N})$ and EVAHEART $(D \sim$ $9.5 \mathrm{~mm}, 50 \mathrm{~N})$.

In a similar context, the biological functionalization of drivelines aims to eradicate DLIs through increased biological compliance. This goal may be achieved by attaching extracellular and cellular components on the surface of the drivelines, recapitulating critical features of skin architecture (Debels et al. 2015; Sheikholeslam et al. 2018). For instance, the biochemical functionalization of 2-dimensional (2D) silicon and velour substrates with type I collagen is shown to reduce non-specific protein adsorption and enhance fibroblast adhesion (Hussain et al. 2016), indicating potential benefits from the dermal functionalization of LVAD drivelines. Similarly, fibroblast seeding on top of 3-dimensional (3D) mock drivelines promoted upward epidermal growth, inhibiting bacterial migration in HSE (Bolle et al. 2020a, b). Overall, the strategy of driveline functionalization can exploit previously recorded cell-material relationships to expedite the design of power transfer systems with enhanced biocompatibility and infectious-resistant effects. 


\section{Engineering new systems of conductive skin}

A significant stepping-stone towards the next generation of power transfer systems will be the design of highly conductive elements within scaffolds of increased biological mimicry. Yet, these devices will not only incur the high risk of infection and FBR, but that of the electrical hazard against fragile biological parts as well. Currently developed conductive systems bear properties that partially protect them against similar problems. For instance, although flexible material systems, the so called "electronic skin", may serve as well-laminated power transfer systems (e.g., coil, solar panels, piezoelectric generators) onto the human skin (e-skin, Fig. 3c), the uncertain biological compatibility and low-power characteristics ( $\mu$ Watts-mWatts) restrain their use in LVAD applications (García Núñez et al. 2019; Hammock et al. 2013; Kim et al. 2011; Li et al. 2016; Zhu et al. 2020).

A different approach constitutes from composite systems that blend high-conductivity constituents with biopolymers to engineer tissue scaffolds with improved electrical properties (Fig.3d) (Guo and Ma 2018; Min et al. 2018; Walker et al. 2019). Following this strategy, the addition of carbon nanotubes and polymer nanofibers in cellular scaffolds has been shown to increase conductivity without disrupting cellular viability (MacDonald et al. 2008; Sirivisoot et al. 2014). Similarly, electrode embedment in conductive biological scaffolds enhanced both the electrical transmission and the anti-fibrotic responses (Cheong et al. 2014). However, in spite of the apparent biological affinity, the achieved conductivity $\left(\sim 10^{-1} \mathrm{~S} / \mathrm{m}\right)$ remains significantly lower than that of metallic wires $\left(10^{7}-10^{8} \mathrm{~S} / \mathrm{m}\right)$ (Sirivisoot et al. 2014), dismissing the use of conductive hydrogels as power transfer systems in LVAD drivelines.

\section{Conductive wires with controlled physical features}

The different limitations associated with the use of drivelines in LVADs urge the design of new power transfer systems to support IMDs without the problem of DLIs. A potential prototype to limit DLIs as well as FBR shall involve the use of skin substitutes with individually incorporated metallic wires (Fig. 3e). The novelty of our proposed solution is centered around the righteous selection and modification of the size and surface characteristics of conductive wires (i.e., material and topography). In particular, the proposed prototype aims to leverage the ability of the skin tissue to more effectively seal and heal around small size objects. Despite the limited amount of data on how the size of drivelines affects the incidence of DLIs (Imamura et al. 2017), small percutaneous objects have lower contact area with the abdominal wall limiting the progress of biofilm migration. In a similar context, thin, sub-millimeter sutures repair skin incisions without significant wound formation (Fig. 4a), while needles and implants of smaller diameter are also shown to reduce the underlying trauma and FBR (Helton et al. 2011). Driven by this evidence, we chose enameled copper wires with significantly smaller diameter $(D=0.2$ and $D=0.4 \mathrm{~mm}$, Distrelec) compared to LVAD drivelines ( $D=6 \mathrm{~mm}$ in HeartMate 3 ) as the main conductive part of our prototype (Fig. 3e). To the extent of our knowledge, this is the first time that a similar configuration of thin conductive wires is proposed as part of a power transfer system in IMDs, and LVADs in particular.

However, apart from the size, the chemical profile of the implanted objects may also lead to adverse complications, such as FBR (Anderson et al. 2008). Because silicone is a rather common material on the surface of medical devices (Curtis and Steichen 2020), we modified our conductive wires by adding an outer layer of silicone (Fig. 4b, c). Yet, silicone surfaces are vulnerable to fibrotic responses (Curtis and Steichen 2020). In effect of that, previous studies modified silicone surfaces with rational topographical details to regulate cell adhesion against fibrosis (Park et al. 2019; Robotti et al. 2018). Motivated by that, we pursued to obtain control over the surface topography of the conductive wires which due to their 3D geometry are not compatible to conventional micropatterning techniques (Quist and Oscarsson 2010). In return, we developed an innovative method of free-form topography to successfully introduce breath features by the condensation of water droplets on top of semi-cured silicone substrates (Fig. 4b, c) (Wu et al. 2021). In contrast with other methods for imprinting breath topography (Kawano et al. 2013; Martínez-Campos et al. 2016), our strategy employs a solvent-free approach that obtains spatial profiles of different features (i.e., depth, diameter, and inter-space distance) on $0.2 \mathrm{~mm}$ and $0.4 \mathrm{~mm}$ wires, respectively (Fig. 4d).

Furthermore, the small diameter of the metallic wires shall strongly reduce their flexural stiffness so to effectively protect the adjacent skin from external forces. On the other hand, lower stiffness entails the risk of larger mechanical movements by the LVAD drivelines at the exit site and the occasional destruction of their electrical insulation (Coyle et al. 2020). For this reason, we developed a customized protocol to assess the electrical resistance of the wires as a function of controllable mechanical deformation (Fig. 4e). In this test, the electrical current conducted from the buffer to the enameled wires shall be indicative of the underlying insulation defects. Since the conducted current is lower than previously reported levels with hazardous effects on the human body (Fish and Geddes 2009), it suggests that the small diameter wires are eligible for further investigation for the generation of new power transfer systems. In 
Fig. 4 Functionalization of thin conductive wires with selected physical characteristics. (a) Commercially available surgical sutures are eminent examples of percutaneous sub-millimeter objects with relatively biocompatible properties. From left to right: monofilament supramid $(0.4 \mathrm{~mm})$ and ethicon PDP $305(0.3 \mathrm{~mm})$ sutures. Ethicon VCP $215(0.3 \mathrm{~mm})$ is made of absorbable vicryl with distinct braided architecture for enhanced adhesion on the contacting tissue. Enameled conductive wires $(\mathrm{W})$ with a diameter of (b) $0.2 \mathrm{~mm}$ and (c) $0.4 \mathrm{~mm}$. Chemical modification with a silicone layer (WS). Physical modification with breath features (WST). (d) Diameter, depth, and inter-space distance of breath features in WST wires were captured by specialized confocal microscopy (von Petersdorff-Campen et al. 2021) and quantified by a custom-made MATLAB protocol (Wu et al. 2021). (e) Scheme of the electromechanical testing protocol for monitoring the insulation damage in response to the deformation of W, WS, and WST wires. $P$ values indicated for $P<0.05$ (*), $P<0.01$ (**), $P<0.001(* * *)$, and $P<0.0001(* * * *)$. Scale bars are $100 \mu \mathrm{m}$ (a)

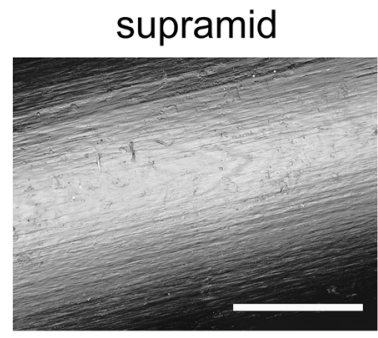

W

(b)
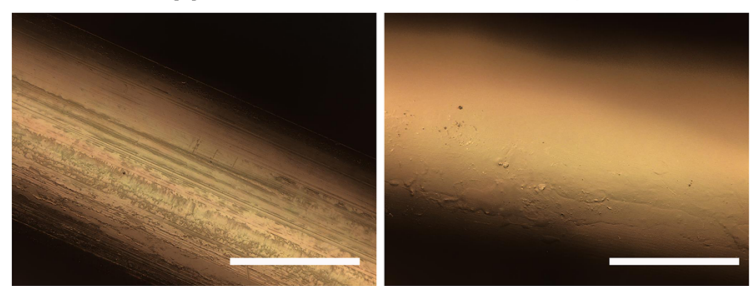

(c)
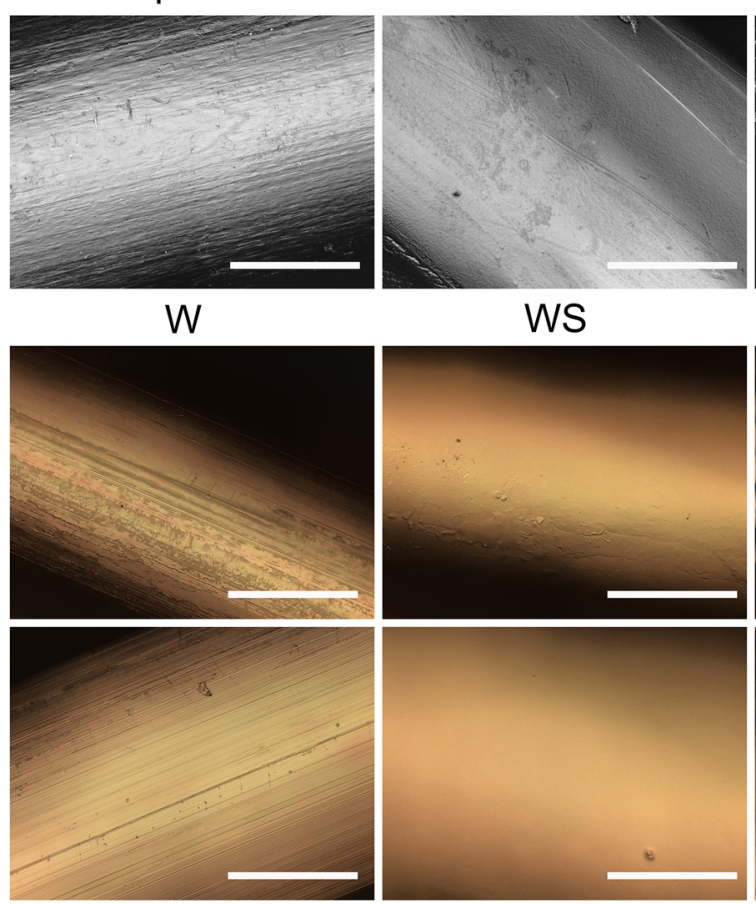

WS
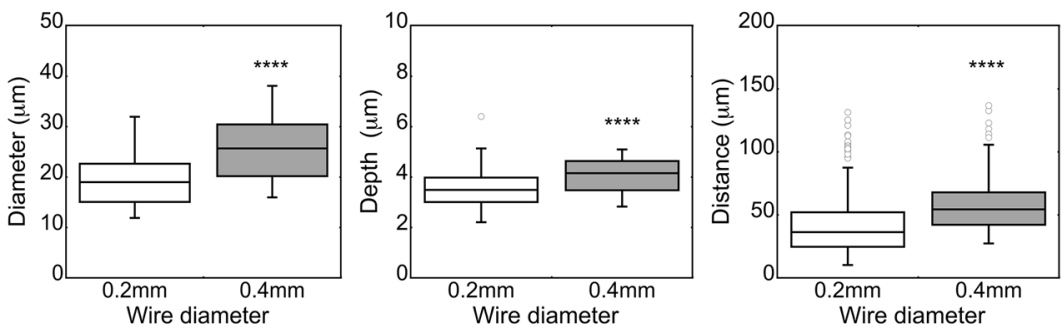

(e)
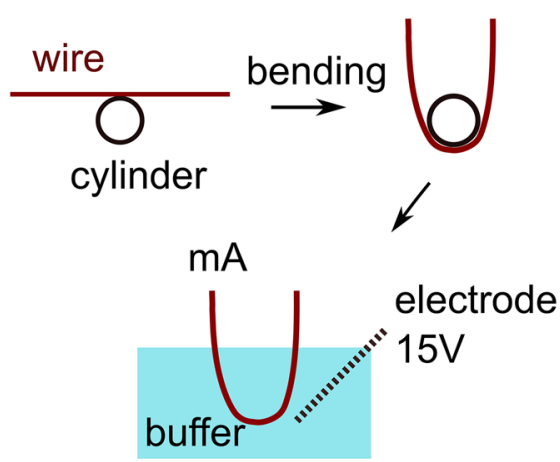

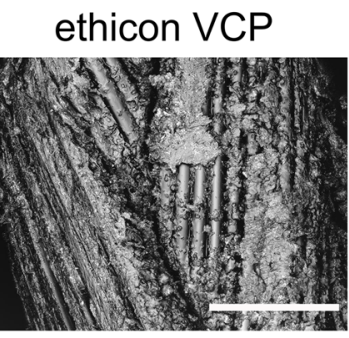

WST
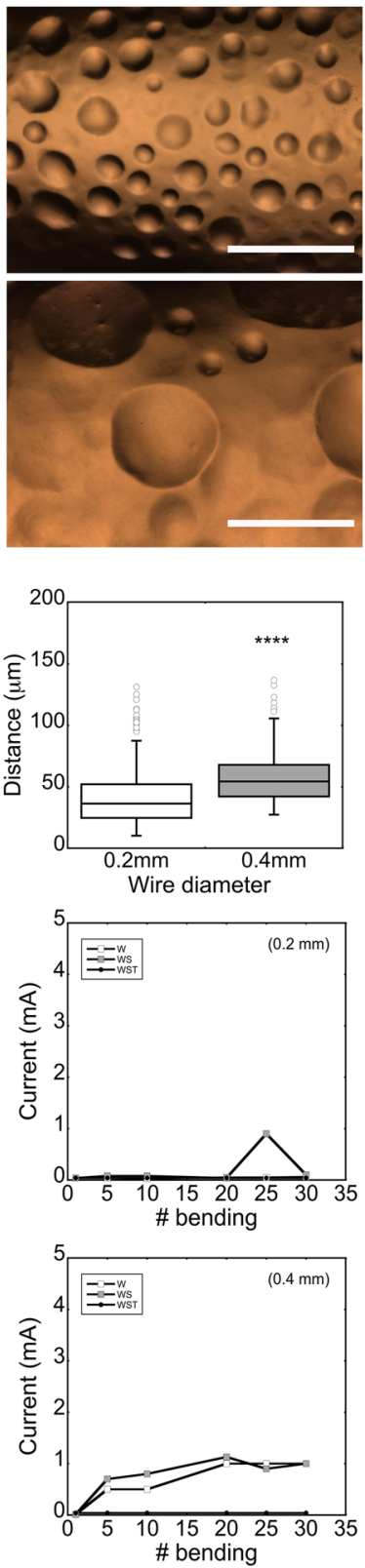

this direction, we also explored the biocompatibility of the wires through an established cytotoxicity assay, according which neurite growth of rat adrenal phaeochromocytoma cells (PC 12) correlates with cell apoptosis in vitro (Bernardi et al. 2017; Ferrari et al. 2010). Our findings demonstrate negligible changes on the length of neurites, suggesting the non-cytotoxic effects of the investigated wires (Fig. 5). Beyond the scope of this review, future studies shall proceed 
Fig. 5 Enamel copper wires induce non-cytotoxic effects in in vitro culture. (a-d) Box-\&Whisker plots for the neurite length $(>20 \mu \mathrm{m})$ grown by PC 12 cells during co-culture with different wire conditions. For all the conditions $P$ value $>0.05$. (e,f) Representative pictures of neurites in PC 12 cells (black arrows). $P$ values indicated for $P<0.05\left(^{*}\right), P<0.01(* *)$, $P<0.001$ (***), and $P<0.0001$ $(* * * *)$. Scale bars are $70 \mu \mathrm{m}$ (a)

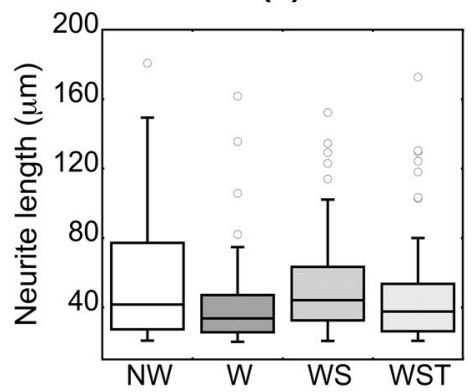

(c)

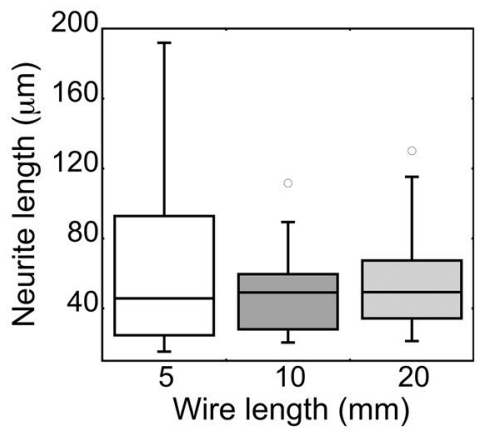

(e)

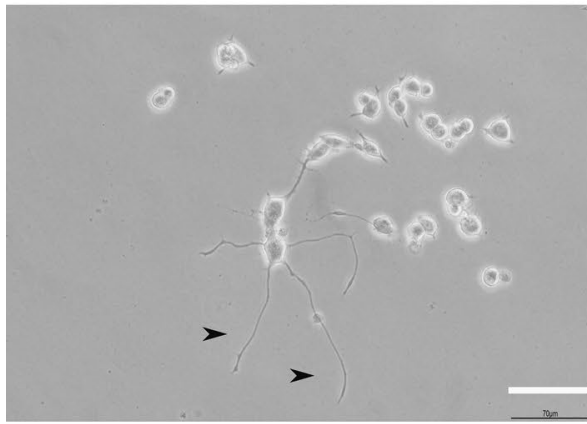

(g)

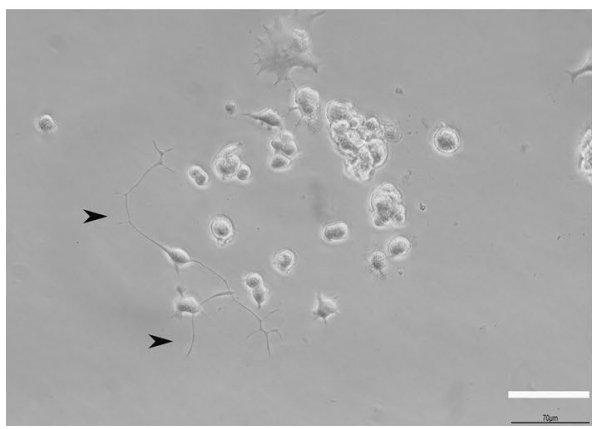

(b)

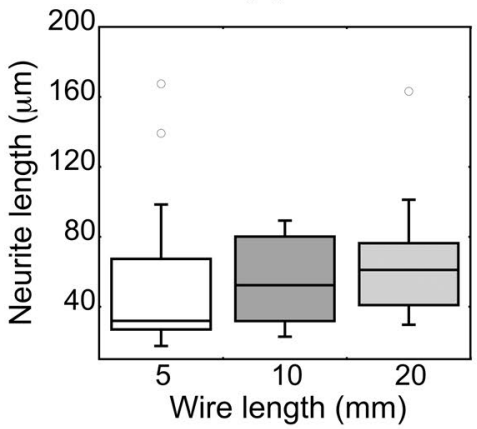

(d)

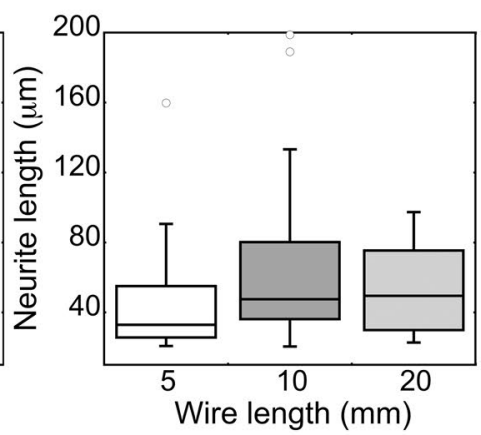

(f)

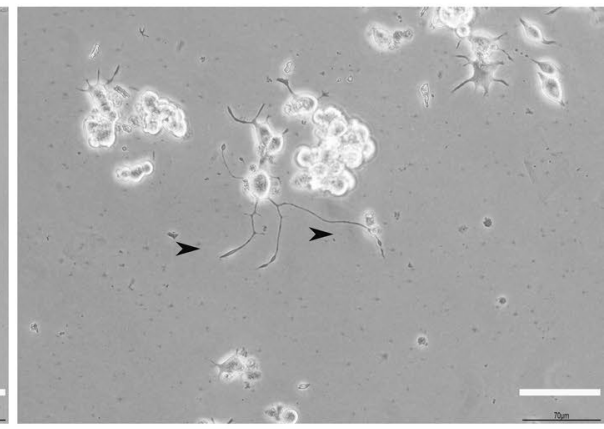

(h)

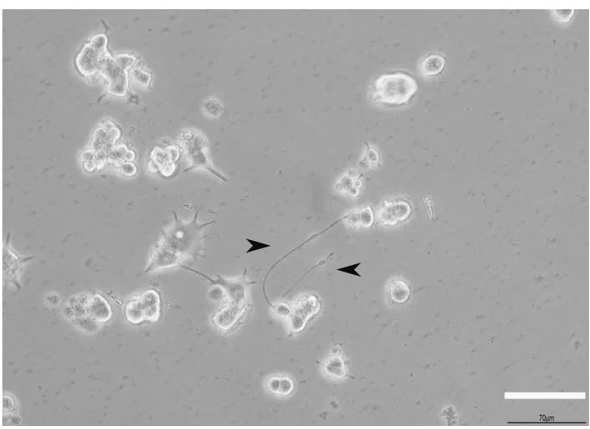

to a thorough characterization of the electromechanical and biological properties of the wires under environmental conditions that resemble those of implanted LVAD drivelines.

\section{Future outlook}

The design of new models of conductive skin is expected to grow along with the need for more advanced clinical protocols against DLIs. Apart from offering a potential solution 
to power LVADs, the design of new systems of conductive skin may expand the capabilities of other life-supporting technologies, such as wearable artificial organs (Gura et al. 2016; Lu et al. 2020). Since infection and FBR are major complications related with IMDs, the functional characteristics of conductive skin shall work against these problems. In this direction, the progress of mechanobiology and tissue engineering provides a guide to engineer systems of conductive skin with minimal tissue morbidity. Specific experimental efforts shall proceed with the formulation of 3D skin substitutes that contain surface-functionalized conductive wires (Fig. 3e) with the capacity to power IMDs without severe complications. The pre-clinical evaluation shall attest the effects of different conductive skin systems in host organisms that are suitable for exploratory LVAD studies. In addition, the use of dynamic bioreactors offers a powerful in vitro strategy to assess the performance of new systems of conductive skin under non-static conditions with controllable mechanical and biological signals (Wahlsten et al. 2021). Overall, the mechanobiology-directed design of conductive skin, in synergy with the development of complementary health technologies, has the potential to revolutionize the capabilities of IMDs and improve patient management against chronic diseases.

Acknowledgements This work is part of the Zurich Heart project under the umbrella of Hochschulmedizin Zürich. In addition, this work was sponsored by grants from the Swiss National Science Foundation (205321_179012 and 205321_188828).

Funding Open Access funding provided by ETH Zurich.

\section{Declarations}

Conflict of interest Xi Wu, Andreas Kourouklis, Raoul Hopf, Edoardo Mazza and Aldo Ferrari have submitted a patent application for protection of the technology described in the manuscript.

Open Access This article is licensed under a Creative Commons Attribution 4.0 International License, which permits use, sharing, adaptation, distribution and reproduction in any medium or format, as long as you give appropriate credit to the original author(s) and the source, provide a link to the Creative Commons licence, and indicate if changes were made. The images or other third party material in this article are included in the article's Creative Commons licence, unless indicated otherwise in a credit line to the material. If material is not included in the article's Creative Commons licence and your intended use is not permitted by statutory regulation or exceeds the permitted use, you will need to obtain permission directly from the copyright holder. To view a copy of this licence, visit http://creativecommons.org/licenses/by/4.0/.

\section{References}

Anderson JM, Rodriguez A, Chang DT (2008) Foreign body reaction to biomaterials. Semin Immunol 20:86-100. https://doi.org/10. 1016/j.smim.2007.11.004

Ashara KC, Shah KV (2016) Elementary of animal model for percutaneous and ocular penetration. Asian Pac J Trop Dis. https://doi. org/10.1016/S2222-1808(16)61174-X

Bamberger $\mathrm{C}$ et al (2005) Activin controls skin morphogenesis and wound repair predominantly via stromal cells and in a concentration-dependent manner via keratinocytes. Am J Pathol 167:733747. https://doi.org/10.1016/S0002-9440(10)62047-0

Ben Amar A, Kouki AB, Cao H (2015) Power approaches for implantable medical devices. Sensors (basel) 15:28889-28914. https:// doi.org/10.3390/s 151128889

Bernardi L, Hopf R, Sibilio D, Ferrari A, Ehret AE, Mazza E (2017) On the cyclic deformation behavior, fracture properties and cytotoxicity of silicone-based elastomers for biomedical applications. Polym Test 60:117-123

Bernhardt AM, Schlöglhofer T, Lauenroth V, Mueller F, Mueller M, Schoede A, Klopsch C (2020) Prevention and early treatment of driveline infections in ventricular assist device patients-The DESTINE staging proposal and the first standard of care protocol. J Crit Care 56:106-112. https://doi.org/10.1016/j.jcrc.2019. 12.014

Biffi M (2019) The never-ending story of CIED infection prevention: shall we WRAP-IT and go? J Cardiovasc Electrophysiol 30:1191-1196. https://doi.org/10.1111/jce.14010

Bolle ECL, Bartnikowski N, Haridas P, Parker TJ, Fraser JF, Gregory SD, Dargaville TR (2020a) Improving skin integration around long-term percutaneous devices using fibrous scaffolds in a reconstructed human skin equivalent model. J Biomed Mater Res B Appl Biomater 108:738-749. https://doi.org/10.1002/ jbm.b.34428

Bolle ECL, Verderosa AD, Dhouib R, Parker TJ, Fraser JF, Dargaville TR, Totsika M (2020b) An in vitro reconstructed human skin equivalent model to study the role of skin integration around percutaneous devices against bacterial infection. Front Microbiol 11:670. https://doi.org/10.3389/fmicb.2020. 00670

Carney EL, Clark JB, Myers JL, Peterson R, Wilson RP, Weiss WJ (2009) Animal model development for the Penn State pediatric ventricular assist device. Artif Organs 33:953-957. https://doi. org/10.1111/j.1525-1594.2009.00896.x

Chandrasekhar A, Kim CS, Naji M, Natarajan K, Hahn JO, Mukkamala $\mathrm{R}$ (2018) Smartphone-based blood pressure monitoring via the oscillometric finger-pressing method. Sci Transl Med. https:// doi.org/10.1126/scitranslmed.aap8674

Cheong GLM, Lim KS, Jakubowicz A, Martens PJ, Poole-Warren LA, Green RA (2014) Conductive hydrogels with tailored bioactivity for implantable electrode coatings. Acta Biomater 10:12161226. https://doi.org/10.1016/j.actbio.2013.12.032

Coyle L et al (2020) Treatment of HeartMate II short-to-shield patients with an ungrounded cable: indications and long-term outcomes. ASAIO J 66:381-387. https://doi.org/10.1097/MAT.0000000000 001012

Curtis J, Steichen SD (2020) 1.3.2B-silicones. In: Wagner WR, Sakiyama-Elbert SE, Zhang G, Yaszemski MJ (eds) Biomaterials science, 4th edn. Academic Press, Cambridge, pp 109-123. https://doi.org/10.1016/B978-0-12-816137-1.00011-8

D'Ovidio TJ, Friederich ARW, de Herrera N, Davis-Hall D, Mann EE, Magin CM (2019) Micropattern-mediated apical guidance accelerates epithelial cell migration to improve healing around percutaneous gastrostomy tubes. Biomed. Phys. Eng. Express 5:065027. https://doi.org/10.1088/2057-1976/ab50d5 
Davenport Huyer L, Pascual-Gil S, Wang Y, Mandla S, Yee B, Radisic M (2020) Advanced strategies for modulation of the materialmacrophage interface. Adv Funct Mater 30:1909331. https://doi. org/10.1002/adfm.201909331

de Vaugelade C et al (2019) Infections in patients using ventricularassist devices: comparison of the diagnostic performance of (18) F-FDG PET/CT scan and leucocyte-labeled scintigraphy. J Nucl Cardiol 26:42-55. https://doi.org/10.1007/s12350-018-1323-7

Dean D et al (2015) Reduction in driveline infection rates: results from the HeartMate II Multicenter Driveline Silicone Skin Interface (SSI) Registry. J Heart Lung Transplant 34:781-789. https://doi. org/10.1016/j.healun.2014.11.021

Debels H, Hamdi M, Abberton K, Morrison W (2015) Dermal matrices and bioengineered skin substitutes: a critical review of current options. Plast Reconstr Surg Glob Open. https://doi.org/10.1097/ GOX.0000000000000219

Dellambra E, Odorisio T, D'Arcangelo D, Failla CM, Facchiano A (2019) Non-animal models in dermatological research. Altex 36:177-202. https://doi.org/10.14573/altex.1808022

Deshayes N, Bloas F, Boissout F, Lecardonnel J, Paris M (2018) 3D In vitro model of the re-epithelialization phase in the woundhealing process. Exp Dermatol 27:460-462. https://doi.org/10. 1111/exd.13390

Dondossola E, Holzapfel BM, Alexander S, Filippini S, Hutmacher DW, Friedl P (2016) Examination of the foreign body response to biomaterials by nonlinear intravital microscopy. Nat Biomed Eng. https://doi.org/10.1038/s41551-016-0007

Dvorak P, Novak M, Kamaryt P, Slana B, Lipoldova J, Dvorak P (2012) Histological findings around electrodes in pacemaker and implantable cardioverter-defibrillator patients: comparison of steroid-eluting and non-steroid-eluting electrodes. Europace 14:117-123. https://doi.org/10.1093/europace/eur274

El-Banayosy A, Arusoglu L, Kizner L, Morshuis M, Tenderich G, Pae WE, Korfer R (2003) Preliminary experience with the LionHeart left ventricular assist device in patients with end-stage heart failure. Ann Thorac Surg 75:1469-1475. https://doi.org/10.1016/ S0003-4975(02)04097-3

Ferrari A, Faraci P, Cecchini M, Beltram F (2010) The effect of alternative neuronal differentiation pathways on $\mathrm{PC} 12$ cell adhesion and neurite alignment to nanogratings. Biomaterials 31:2565-2573. https://doi.org/10.1016/j.biomaterials.2009.12.010

Fish RM, Geddes LA (2009) Conduction of electrical current to and through the human body: a review. Eplasty 9:e44-e44

Fleissner F, Avsar M, Malehsa D, Strueber M, Haverich A, Schmitto JD (2013) Reduction of driveline infections through doubled driveline tunneling of left ventricular assist devices. Artif Organs 37:102-107. https://doi.org/10.1111/aor.12036

Fukano $\mathrm{Y}$ et al (2010) Epidermal and dermal integration into spheretemplated porous poly(2-hydroxyethyl methacrylate) implants in mice. J Biomed Mater Res Part A 94a:1172-1186. https://doi. org/10.1002/jbm.a.32798

García Núñez C, Manjakkal L, Dahiya R (2019) Energy autonomous electronic skin. NPJ Flex Electron 3:1. https://doi.org/10.1038/ s41528-018-0045-X

Goldstein DJ, Naftel D, Holman W, Bellumkonda L, Pamboukian SV, Pagani FD, Kirklin J (2012) Continuous-flow devices and percutaneous site infections: clinical outcomes. J Heart Lung Transplant 31:1151-1157. https://doi.org/10.1016/j.healun.2012. 05.004

Grada A, Mervis J, Falanga V (2018) Research techniques made simple: animal models of wound healing. J Investig Dermatol. https://doi.org/10.1016/j.jid.2018.08.005

Greenfeld JI, Sampath L, Popilskis SJ, Brunnert SR, Stylianos S, Modak S (1995) Decreased bacterial adherence and biofilm formation on chlorhexidine and silver sulfadiazine-impregnated central venous catheters implanted in swine. Crit Care
Med 23:894-900. https://doi.org/10.1097/00003246-19950 5000-00018

Griffin MF, desJardins-Park HE, Mascharak S, Borrelli MR, Longaker MT (2020) Understanding the impact of fibroblast heterogeneity on skin fibrosis. Dis Model Mech. https://doi.org/10.1242/ dmm.044164

Großhauser J, Reiter K, Große-Siestrup C, Kikhney J, Kertzscher U, Affeld K (2015) Bionic approach for the prevention of exit-site infections of percutaneous devices. Biomed Technol. https://doi. org/10.1515/bmt-2014-0062

Guimarães CF, Gasperini L, Marques AP, Reis RL (2020) The stiffness of living tissues and its implications for tissue engineering. Nat Rev Mater 5:351-370. https://doi.org/10.1038/ s41578-019-0169-1

Guo B, Ma PX (2018) Conducting polymers for tissue engineering. Biomacromol 19:1764-1782. https://doi.org/10.1021/acs.biomac. 8 b00276

Gura V et al (2016) A wearable artificial kidney for patients with endstage renal disease. JCI Insight 1(8):e86397. https://doi.org/10. 1172/jci.insight. 86397

Haddad O, Pham AN, Thomas M, Ali M, Sareyyupoglu B, El-Sayed Ahmed MM, Pham SM (2020) Absorbable antibiotic beads as an adjuvant therapy in treating ventricular assist devices driveline infection: a case report. J Card Surg 35:2073-2076. https://doi. org/10.1111/jocs. 14778

Hammock ML, Chortos A, Tee BCK, Tok JBH, Bao ZA (2013) 25th anniversary article: the evolution of electronic skin (e-skin): a brief history. Des Consid Recent Prog Adv Mater 25:5997-6037. https://doi.org/10.1002/adma.201302240

Hannan MM et al (2011) Working formulation for the standardization of definitions of infections in patients using ventricular assist devices. J Heart Lung Transplant 30:375-384. https://doi.org/ 10.1016/j.healun.2011.01.717

Hannan MM et al (2019) Epidemiology of infection in mechanical circulatory support: a global analysis from the ISHLT Mechanically Assisted Circulatory Support Registry. J Heart Lung Transplant 38:364-373. https://doi.org/10.1016/j.healun.2019.01.007

Helton KL, Ratner BD, Wisniewski NA (2011) Biomechanics of the sensor-tissue interface-effects of motion, pressure, and design on sensor performance and foreign body response-part II: examples and application. J Diabetes Sci Technol 5:647-656. https://doi.org/10.1177/193229681100500318

Hilker L, von Woedtke T, Weltmann KD, Wollert HG (2017) Cold atmospheric plasma: a new tool for the treatment of superficial driveline infections. Eur J Cardiothorac Surg 51:186-187. https://doi.org/10.1093/ejcts/ezw212

Hussain A, Curry B, Cahalan L, Minkin S, Gartner M, Cahalan P (2016) Development and in vitro evaluation of infection resistant materials: a novel surface modification process for silicone and Dacron. J Biomater Appl. https://doi.org/10.1177/08853 28215607378

Imamura T, Murasawa T, Kawasaki H, Kashiwa K, Kinoshita O, Nawata K, Ono M (2017) Correlation between driveline features and driveline infection in left ventricular assist device selection. J Artif Organs 20:34-41. https://doi.org/10.1007/ s10047-016-0923-8

Isenhath SN et al (2007) A mouse model to evaluate the interface between skin and a percutaneous device. J Biomed Mater Res A 83:915-922. https://doi.org/10.1002/jbm.a.31391

Jahanshahi M et al (2020) An engineered infected epidermis model for in vitro study of the skin's pro-inflammatory response. Micromachines (basel). https://doi.org/10.3390/mi11020227

Jarvik R, Westaby S, Katsumata T, Pigott D, Evans RD (1998) LVAD power delivery: a percutaneous approach to avoid infection. Ann Thorac Surg 65:470-473. https://doi.org/10.1016/s00034975(97)01343-x 
Johansson F, Wallman L, Danielsen N, Schouenborg J, Kanje M (2009) Porous silicon as a potential electrode material in a nerve repair setting: tissue reactions. Acta Biomater 5:2230-2237

Kawano T, Nakamichi Y, Fujinami S, Nakajima K, Yabu H, Shimomura M (2013) Mechanical regulation of cellular adhesion onto honeycomb-patterned porous scaffolds by altering the elasticity of material surfaces. Biomacromol 14:1208-1213. https:// doi.org/10.1021/bm400202d

Kaylan KB, Kourouklis AP, Underhill GH (2017) A high-throughput cell microarray platform for correlative analysis of cell differentiation and traction forces. J vis Exp. https://doi.org/10.3791/ 55362

Kilo J, Dumfarth J, Höfer D, Grimm M (2020) Successful treatment of driveline infection with vacuum-assisted closure therapy and instillation therapy. Thorac Cardiovasc Surg Rep 9:e29-e32. https://doi.org/10.1055/s-0040-1713731

Kim DH et al (2011) Epidermal electronics. Science 333:838-843. https://doi.org/10.1126/science.1206157

Kim BS, Gao G, Kim JY, Cho DW (2019) 3D cell printing of perfusable vascularized human skin equivalent composed of epidermis, dermis, and hypodermis for better structural recapitulation of native skin. Adv Healthc Mater. https://doi.org/10.1002/adhm. 201801019

Kirklin JK et al (2017) Eighth annual INTERMACS report: special focus on framing the impact of adverse events. J Heart Lung Transplant 36:1080-1086. https://doi.org/10.1016/j.healun.2017. 07.005

Kitao T et al (2011) In vivo evaluation of the "TinyPump" as a pediatric left ventricular assist device. Artif Organs 35:543-553. https://doi.org/10.1111/j.1525-1594.2010.01192.x

Kourouklis AP, Lerum RV, Bermudez H (2014) Cell adhesion mechanisms on laterally mobile polymer films. Biomaterials 35:48274834. https://doi.org/10.1016/j.biomaterials.2014.02.052

Koval CE, Stosor V, Practice AICo (2019) Ventricular assist devicerelated infections and solid organ transplantation-Guidelines from the American Society of Transplantation Infectious Diseases Community of Practice. Clin Transplant 33:e13552. https:// doi.org/10.1111/ctr.13552

Krahn AD et al (2018) Prevention of arrhythmia device infection trial: the PADIT trial. J Am Coll Cardiol 72:3098-3109. https://doi. org/10.1016/j.jacc.2018.09.068

Kusne S et al (2017) An ISHLT consensus document for prevention and management strategies for mechanical circulatory support infection. J Heart Lung Transplant 36:1137-1153. https://doi. org/10.1016/j.healun.2017.06.007

Kwon SH, Padmanabhan J, Gurtner GC (2018) Chapter 14-Mechanobiology of skin diseases and wound healing. In: Verbruggen SW (ed) Mechanobiology in health and disease. Academic Press, Cambridge, pp 415-448. https://doi.org/10.1016/B978-0-12812952-4.00014-3

Lee S, Fukamachi K, Golding L, Moazami N, Starling RC (2013) Left ventricular assist devices: from the bench to the clinic. Cardiology 125:1-12. https://doi.org/10.1159/000346865

Letzen B, Park J, Tuzun Z, Bonde P (2018) Design and Development of a Miniaturized Percutaneously Deployable Wireless Left Ventricular Assist Device: Early Prototypes and Feasibility Testing. ASAIO J 64:147-153. https://doi.org/10.1097/Mat.0000000000 000669

Leuck AM (2015) Left ventricular assist device driveline infections: recent advances and future goals. J Thorac Dis 7:2151-2157. https://doi.org/10.3978/j.issn.2072-1439.2015.11.06

Li C et al (2016) Wearable energy-smart ribbons for synchronous energy harvest and storage. Nat Commun. https://doi.org/10. 1038/ncomms 13319
Li L, Eyckmans J, Chen CS (2017) Designer biomaterials for mechanobiology. Nat Mater 16:1164-1168. https://doi.org/10.1038/ nmat5049

Li JM, Li Y, Tholakanahalli V, Benditt DG (2020) Fibrous encapsulation of defibrillation electrode and elevated high-voltage impedance in patients with a subcutaneous implantable cardioverterdefibrillator HeartRhythm. Case Rep 6:148-152. https://doi.org/ 10.1016/j.hrcr.2019.11.009

Liu LY, Chen G, Chao T, Ratner BD, Sage EH, Jiang SY (2008) Reduced foreign body reaction to implanted biomaterials by surface treatment with oriented osteopontin. J Biomater Sci Polym Ed 19:821-835. https://doi.org/10.1163/156856208784522083

Lu L, Zhang JY, Xie Y, Gao F, Xu S, Wu XH, Ye ZW (2020) Wearable health devices in health care: Narrative systematic review. JMIR Mhealth Uhealth 8:e18907

Maboni G et al (2017) A novel 3D skin explant model to study anaerobic bacterial infection. Front Cell Infect Microbiol 7:404. https:// doi.org/10.3389/fcimb.2017.00404

MacDonald RA, Voge CM, Kariolis M, Stegemann JP (2008) Carbon nanotubes increase the electrical conductivity of fibroblastseeded collagen hydrogels. Acta Biomater 4:1583-1592. https:// doi.org/10.1016/j.actbio.2008.07.005

Maly J, Szarszoi O, Netuka I, Dorazilova Z, Pirk J (2014) Fungal infections associated with long-term mechanical circulatory supportdiagnosis and management. J Card Surg 29:95-100. https://doi. org/10.1111/jocs. 12258

Martínez-Campos E et al (2016) Toward cell selective surfaces: cell adhesion and proliferation on breath figures with antifouling surface chemistry. ACS Appl Mater Interfaces. https://doi.org/10. 1021/acsami.5b12832

McCandless SP et al (2015) Comparing velour versus silicone interfaces at the driveline exit site of HeartMate II devices: infection rates, histopathology, and ultrastructural aspects. Cardiovasc Pathol. https://doi.org/10.1016/j.carpath.2014.07.011

McGee E Jr, Chorpenning K, Brown MC, Breznock E, Larose JA, Tamez D (2014) vivo evaluation of the HeartWare MVAD Pump. J Heart Lung Transplant 33:366-371. https://doi.org/10.1016/j. healun.2013.10.003

Mehta SM et al (2001) The LionHeart LVD-2000: a completely implanted left ventricular assist device for chronic circulatory support. Ann Thorac Surg 71:S156-S161. https://doi.org/10. 1016/S0003-4975(00)02641-2

Min JH, Patel M, Koh WG (2018) Incorporation of conductive materials into hydrogels for tissue engineering applications. Polymers. https://doi.org/10.3390/polym 10101078

Miyazaki H, Tsunoi Y, Akagi T, Sato S, Akashi M, Saitoh D (2019) A novel strategy to engineer pre-vascularized 3-dimensional skin substitutes to achieve efficient, functional engraftment. Sci Rep. https://doi.org/10.1038/s41598-019-44113-6

Moniz T, Costa Lima SA, Reis S (2020) Human skin models: from healthy to disease-mimetic systems; characteristics and applications. Br J Pharmacol 177:4314-4329. https://doi.org/10. 1111/bph.15184

Monreal G, Sherwood LC, Sobieski MA, Giridharan GA, Slaughter MS, Koenig SC (2014) Large animal models for left ventricular assist device research and development. ASAIO J 60:2-8. https://doi.org/10.1097/MAT.0000000000000005

Mulzer J, Trampuz A, Potapov EV (2020) Treatment of chronic left ventricular assist device infection with local application of bacteriophages. Eur J Cardiothorac Surg 57:1003-1004. https:// doi.org/10.1093/ejcts/ezz295

Murray RZ, West ZE, Cowin AJ, Farrugia BL (2019) Development and use of biomaterials as wound healing therapies. Burns Trauma 7:2-2. https://doi.org/10.1186/s41038-018-0139-7

Park C et al (2019) Reduced fibrous capsule formation at nanoengineered silicone surfaces via tantalum ion implantation. 
Biomater Sci 7:2907-2919. https://doi.org/10.1039/c9bm0 $0427 \mathrm{k}$

Pavlovic NV, Randell T, Madeira T, Hsu S, Zinoviev R, Abshire M (2019) Risk of left ventricular assist device driveline infection: a systematic literature review. Heart Lung 48:90-104. https:// doi.org/10.1016/j.hrtlng.2018.11.002

Pensalfini M, Haertel E, Hopf R, Wietecha M, Werner S, Mazza E (2018) The mechanical fingerprint of murine excisional wounds. Acta Biomater 65:226-236. https://doi.org/10.1016/j. actbio.2017.10.021

Picha GJ, Drake RF (1996) Pillared-surface microstructure and softtissue implants: effect of implant site and fixation. J Biomed Mater Res 30:305-312. https://doi.org/10.1002/(SICI)10974636(199603)30:3\%3c305::AID-JBM5\%3e3.0.CO;2-U

Pieri M et al (2016) Surgical management of driveline infections in patients with left ventricular assist devices. J Card Surg 31:765-771. https://doi.org/10.1111/jocs. 12860

Ponikowski P et al (2016) 2016 ESC Guidelines for the diagnosis and treatment of acute and chronic heart failure: The Task Force for the diagnosis and treatment of acute and chronic heart failure of the European Society of Cardiology (ESC). Developed with the special contribution of the Heart Failure Association (HFA) of the ESC. Eur J Heart Fail 18:891-975. https://doi. org/10.1002/ejhf.592

Popov L, Kovalski J, Grandi G, Bagnoli F, Amieva MR (2014) Three-dimensional human skin models to understand Staphylococcus aureus skin colonization and infection. Front Immunol 5:41. https://doi.org/10.3389/fimmu.2014.00041

Pya Y et al (2019) First human use of a wireless coplanar energy transfer coupled with a continuous-flow left ventricular assist device. J Heart Lung Transplant 38:339-343

Qu Y et al (2020) Characterization of infected, explanted ventricular assist device drivelines: the role of biofilms and microgaps in the driveline tunnel. J Heart Lung Transplant 39:1289-1299. https://doi.org/10.1016/j.healun.2020.07.015

Qu Y, Peleg AY, McGiffin D (2021) Ventricular assist device-specific infections. J Clin Med 10:453

Quist AP, Oscarsson S (2010) Micropatterned surfaces: techniques and applications in cell biology. Expert Opin Drug Discov 5:569581. https://doi.org/10.1517/17460441.2010.489606

Ragelle $\mathrm{H}$ et al (2018) Surface tension-assisted additive manufacturing. Nat Commun 9:1184. https://doi.org/10.1038/ s41467-018-03391-w

Rahmati M, Blaker JJ, Lyngstadaas SP, Mano JF, Haugen HJ (2020) Designing multigradient biomaterials for skin regeneration. Mater Today Adv 5:100051. https://doi.org/10.1016/j.mtadv. 2019.100051

Rakita A, Nikolic N, Mildner M, Matiasek J, Elbe-Burger A (2020) Re-epithelialization and immune cell behaviour in an ex vivo human skin model. Sci Rep 10:1. https://doi.org/10.1038/ s41598-019-56847-4

Randall MJ, Jungel A, Rimann M, Wuertz-Kozak K (2018) Advances in the biofabrication of 3D skin in vitro: healthy and pathological models. Front Bioeng Biotechnol 6:154

Robotti F et al (2018) A micron-scale surface topography design reducing cell adhesion to implanted materials. Sci Rep 8:10887. https://doi.org/10.1038/s41598-018-29167-2

Robotti F et al (2020) Microengineered biosynthesized cellulose as anti-fibrotic in vivo protection for cardiac implantable electronic devices. Biomaterials 229:119583. https://doi.org/10.1016/j. biomaterials.2019.119583

Rodrigues M, Kosaric N, Bonham CA, Gurtner GC (2019) Wound healing: a cellular perspective. Physiol Rev 99:665-706. https:// doi.org/10.1152/physrev.00067.2017

Rousselle P, Braye F, Dayan G (2019) Re-epithelialization of adult skin wounds: cellular mechanisms and therapeutic strategies.
Adv Drug Deliv Rev 146:344-365. https://doi.org/10.1016/j. addr.2018.06.019

Saleh LS, Bryant SJ (2017) In vitro and in vivo models for assessing the host response to biomaterials. Drug Discov Today Dis Models 24:13-21. https://doi.org/10.1016/j.ddmod.2018.04.002

Sanders JE, Bale SD, Neumann T (2002) Tissue response to microfibers of different polymers: polyester, polyethylene, polylactic acid, and polyurethane. J Biomed Mater Res 62:222-227. https://doi. org/10.1002/jbm.10285

Schaudinn C et al (2017) Development, standardization and testing of a bacterial wound infection model based on ex vivo human skin. PLoS One 12:e0186946. https://doi.org/10.1371/journal. pone. 0186946

Schmid Daners M et al (2017) Left ventricular assist devices: challenges toward sustaining long-term patient care. Ann Biomed Eng 45:1836-1851. https://doi.org/10.1007/s10439-017-1858-9

Schoenrath F et al (2020) Fluorescence in situ hybridization and polymerase chain reaction to detect infections in patients with left ventricular assist devices. ASAIO J. https://doi.org/10.1097/mat. 0000000000001260

Sezai A et al (2020) New treatment for driveline infection following implantation of a ventricular assist device. Heart Surg Forum 23:E132-e134. https://doi.org/10.1532/hsf.2899

Shaw TJ, Martin P (2009) Wound repair at a glance. J Cell Sci 122:3209. https://doi.org/10.1242/jcs.031187

Sheikholeslam M, Wright MEE, Jeschke MG, Amini-Nik S (2018) Biomaterials for skin substitutes. Adv Healthc Mater. https://doi. org/10.1002/adhm.201700897

Sirivisoot S, Pareta R, Harrison BS (2014) Protocol and cell responses in three-dimensional conductive collagen gel scaffolds with conductive polymer nanofibres for tissue regeneration. Interface Focus 4:20130050. https://doi.org/10.1098/rsfs.2013.0050

Tarakji KG et al (2019) Antibacterial envelope to prevent cardiac implantable device infection. N Engl J Med 380:1895-1905. https://doi.org/10.1056/NEJMoa1901111

Ten Hove D et al (2021) The value of (18)F-FDG PET/CT for the diagnosis of device-related infections in patients with a left ventricular assist device: a systematic review and meta-analysis. Eur J Nucl Med Mol Imaging 48:241-253. https://doi.org/10.1007/ s00259-020-04930-8

Ternullo S, de Weerd L, Flaten GE, Holsaeter AM, Skalko-Basnet N (2017) The isolated perfused human skin flap model: a missing link in skin penetration studies? Eur J Pharm Sci 96:334-341. https://doi.org/10.1016/j.ejps.2016.10.003

Toba FA, Akashi H, Arrecubieta C, Lowy FD (2011) Role of biofilm in Staphylococcus aureus and Staphylococcus epidermidis ventricular assist device driveline infections. J Thorac Cardiovasc Surg 141:1259-1264. https://doi.org/10.1016/j.jtcvs.2010.07.016

Topol EJ (2019) A decade of digital medicine innovation. Sci Transl Med. https://doi.org/10.1126/scitranslmed.aaw7610

Torres JP, Senejani AG, Gaur G, Oldakowski M, Murali K, Sapi E (2020) Ex vivo murine skin model for B. burgdorferi. Biofilm Antibiot (basel). https://doi.org/10.3390/antibiotics9090528

Trampuz ANR, Potapov E, Schoenrath F (2020) Pocket guide to diagnosis \& treatment of ventricula assist device (VAD) infections. https://pro-implant.org/tools/pocket-guide/7. Accessed 26 Jan 2021

Tsai HC, Chang GRL, Fan HC, Ou-Yang H, Huang LC, Wu SC, Chen CM (2019) A mini-pig model for evaluating the efficacy of autologous platelet patches on induced acute full thickness wound healing. BMC Vet Res. https://doi.org/10.1186/ s12917-019-1932-7

Tschumperlin DJ, Ligresti G, Hilscher MB, Shah VH (2018) Mechanosensing and fibrosis. J Clin Investig 128:74-84. https://doi. org/10.1172/JCI93561 
Tuzun E, Roberts K, Cohn WE, Sargin M, Gemmato CJ, Radovancevic B, Frazier OH (2007) vivo evaluation of the HeartWare centrifugal ventricular assist device. Tex Heart Inst J 34:406-411

Tylek T, Blum C, Hrynevich A, Schlegelmilch K, Schilling T, Dalton PD, Groll J (2020) Precisely defined fiber scaffolds with $40 \mu \mathrm{m}$ porosity induce elongation driven M2-like polarization of human macrophages. Biofabrication 12:025007. https://doi.org/10.1088/ 1758-5090/ab5f4e

Vodička P et al (2005) The miniature pig as an animal model in biomedical research. Ann N Y Acad Sci. https://doi.org/10.1196/ annals.1334.015

von Bayern MP et al (2008) Development of a murine ventricular assist device transcutaneous drive-line model. J Heart Lung Transplant 27:812-814. https://doi.org/10.1016/j.healun.2008.04.003

von Petersdorff-Campen K, Abeken J, de Zelicourt D, Kurtcuoglu V, Meboldt M, Schmid Daners M (2021) Vitro testing and comparison of additively manufactured polymer impellers for the CentriMag blood pump. ASAIO J 67:306-313. https://doi.org/ 10.1097/MAT.0000000000001220

Wahlsten A, Pensalfini M, Stracuzzi A, Restivo G, Hopf R, Mazza E (2019) On the compressibility and poroelasticity of human and murine skin. Biomech Model Mechanobiol 18:1079-1093. https://doi.org/10.1007/s10237-019-01129-1

Wahlsten A, Rütsche D, Nanni M, Giampietro C, Biedermann T, Reichmann E, Mazza E (2021) Mechanical stimulation induces rapid fibroblast proliferation and accelerates the early maturation of human skin substitutes. Biomaterials. https://doi.org/10.1016/j. biomaterials.2021.120779

Walker BW, Lara RP, Mogadam E, Yu CH, Kimball W, Annabi N (2019) Rational design of microfabricated electroconductive hydrogels for biomedical applications. Prog Polym Sci 92:135157. https://doi.org/10.1016/j.progpolymsci.2019.02.007

Ward WK, Slobodzian EP, Tiekotter KL, Wood MD (2002) The effect of microgeometry, implant thickness and polyurethane chemistry on the foreign body response to subcutaneous implants. Biomaterials 23:4185-4192. https://doi.org/10.1016/s0142-9612(02) 00160-6

Waters BH, Smith JR, Bonde P (2014) Innovative free-range resonant electrical energy delivery system (FREE-D System) for a ventricular assist device using wireless power. ASAIO J 60:31-37. https://doi.org/10.1097/Mat.0000000000000029

Waters BH et al (2018) Electrical power to run ventricular assist devices using the Free-range Resonant Electrical Energy
Delivery system. J Heart Lung Transplant 37:1467-1474. https:// doi.org/10.1016/j.healun.2018.08.007

Weigel T et al (2018) A three-dimensional hybrid pacemaker electrode seamlessly integrates into engineered, functional human cardiac tissue in vitro. Sci Rep. https://doi.org/10.1038/ s41598-018-32790-8

Weiss WJ et al (2012) Chronic in vivo testing of the Penn State infant ventricular assist device. ASAIO J 58:65-72. https://doi.org/10. 1097/MAT.0b013e318239feb4

Wert L et al (2018) Reduction of driveline infections through doubled driveline tunneling of left ventricular assist devices-5-year follow-up. J Thorac Dis 10:S1703-s1710. https://doi.org/10.21037/ jtd.2018.03.127

Wietecha MS et al (2020) Activin-mediated alterations of the fibroblast transcriptome and matrisome control the biomechanical properties of skin wounds. Nat Commun 11:2604. https://doi.org/10. 1038/s41467-020-16409-z

Wu X et al (2021) A free-form patterning method enabling endothelialization under dynamic flow. Biomaterials 273:120816. https:// doi.org/10.1016/j.biomaterials.2021.120816

Yang Y et al (2020) A laser-engraved wearable sensor for sensitive detection of uric acid and tyrosine in sweat. Nat Biotechnol 38:217-224. https://doi.org/10.1038/s41587-019-0321-x

Yoon DJ et al (2019) A tractable, simplified ex vivo human skin model of wound infection. Wound Repair Regen 27:421-425. https:// doi.org/10.1111/wrr.12712

Zhu MM, Lou MN, Yu JY, Li ZL, Ding B (2020) Energy autonomous hybrid electronic skin with multi-modal sensing capabilities. Nano Energy. https://doi.org/10.1016/j.nanoen.2020.105208

Zierer A et al (2007) Late-onset driveline infections: The Achilles' heel of prolonged left ventricular assist device support. Ann Thorac Surg. https://doi.org/10.1016/j.athoracsur.2007.03.085

Zinoviev R, Lippincott CK, Keller SC, Gilotra NA (2020) In full flow: left ventricular assist device infections in the modern era. Open Forum Infect Dis 7:ofaa124. https://doi.org/10.1093/ofid/ofaa124

Publisher's Note Springer Nature remains neutral with regard to jurisdictional claims in published maps and institutional affiliations. 